\title{
EVALUATION OF SORGHUM STRAW HEMICELLULOSIC HYDROLYSATE FOR BIOTECHNOLOGICAL PRODUCTION OF XYLITOL BY Candida guilliermondii
}

\author{
L. Sene ${ }^{1 *}$, P.V. Arruda ${ }^{2}$, S.M.M. Oliveira ${ }^{1}$, M.G.A. Felipe ${ }^{2}$ \\ ${ }^{1}$ Universidade Estadual do Oeste do Paraná, Cascavel, PR, Brasil; ${ }^{2}$ Escola de Engenharia de Lorena, Universidade de São Paulo, \\ Lorena, SP, Brasil.
}

Submitted: May 13, 2010; Returned to authors for corrections: December 22, 2010; Approved: May 16, 2011.

\begin{abstract}
A preliminary study on xylitol production by Candida guilliermondii in sorghum straw hemicellulosic hydrolysate was performed. Hydrolysate had high xylose content and inhibitors concentrations did not exceed the commonly found values in other hemicellulosic hydrolysates. The highest xylitol yield $(0.44 \mathrm{~g} / \mathrm{g})$ and productivity $(0.19 \mathrm{~g} / \mathrm{Lh})$ were verified after 72 hours.
\end{abstract}

Key words: sorghum straw, hemicellulosic hydrolysate, xylose, xylitol, Candida guilliermondii.

Xylitol is a sweetener with important properties such as anticariogenicity and metabolism not insulin-dependent [7]. Xylitol is commercially produced from chemical catalysis of xylose, obtained from xylan-rich lignocellulosic materials [9]. Several xylose-xylitol fermenting microorganisms were identified, among which several species of yeasts were recognized as good xylitol producers, especially members of the genus Candida because of the high efficiencies obtained during the conversion of pure xylose and hemicellulosic hydrolysates [3]. The species Candida guilliermondii has been continuously evaluated for the xylitol production in hemicellulosic hydrolysates from different lignocellulosic materials $[10,16,25]$.

Dilute acid hydrolysis is a method commonly used for solubilization of sugars present in hemicellulose. Studies have demonstrated that the biotechnological production of xylitol from lignocellulosic residues is influenced by the type of hemicellulosic hydrolysate, due mainly to the presence of different concentrations of toxic compounds released during the hydrolytic process: acetic acid, released by hemicellulose structure; two most common furaldehydes, HMF (5hydroxymethyl-2-furaldehyde) and furfural (2-furaldehyde), formed at severe hydrolysis conditions from hexoses and pentoses, respectively, and phenolic compounds, formed during partial lignin breakdown [3]. These compounds inhibit microbial metabolism due to their concentrations in the medium [4,17].

Sorghum straw is a renewable and cheap resource, commonly used as livestock feed. However, it has scarcely been studied as raw material for biological processes. Major studies on biotechnological utilization of sorghum straw deals with furfural production [24], cellulase-free xylanase production in solid-state fermentation - SSF [22], ethanol production by simultaneous saccharification with commercial cellulase and fermentation (SFS) [1], ethanol production by SSF of untreated and treated (delignified) sorghum stover [13]

*Corresponding Author. Mailing address: PGEAGRI/UNIOESTE, Rua Universitária 2069, Cascavel, PR, Brazil cep 85819-110.; Tel: +55 45 3220-3226.; Email: luciane.sene@unioeste.br 
and xylitol production by Candida parapsilosis [19]. Studies on the hydrolysis of hemicelullosic fraction of sorghum straw $[6,23]$ show a possible alternative source of xylose to several biotechnological processes.

As the lignocellulosic materials are rather heterogeneous in terms of chemical composition, the objective of this study was to investigate the viability of using forage sorghum straw hemicellulosic hydrolysate for xylitol production by the yeast C. guilliermondii.

For inoculum preparation, the yeast Candida guilliermondii FTI 20037 was grown in 125 mL-Erlenmeyers flasks, containing $50 \mathrm{~mL}$ of medium formulated with xylose $(30 \mathrm{~g} / \mathrm{L})$, rice bran extract $(20 \mathrm{~g} / \mathrm{L}),\left(\mathrm{NH}_{4}\right)_{2} \mathrm{SO}_{4}(2 \mathrm{~g} / \mathrm{L})$ and $\mathrm{CaCl}_{2} .2 \mathrm{H}_{2} \mathrm{O}(0.1 \mathrm{~g} / \mathrm{L})$ at $\mathrm{pH} 5.5$ and incubated in a rotary shaker $(200 \mathrm{rpm})$ at $30^{\circ} \mathrm{C}$ for 24 hours. Then cells were separated by centrifugation at 2,900 $\mathrm{g}$ for 20 minutes, rinsed twice with sterile distilled water and resuspended in an adequate volume of distilled water. The initial cell concentration for the experiment was $1.0 \mathrm{~g} / \mathrm{L}$.

Forage sorghum straw was hydrolyzed in a 350 L AISI 316 stainless steel reactor at $121^{\circ} \mathrm{C}$ during 10 minutes with 100 $\mathrm{mg} \mathrm{H}_{2} \mathrm{SO}_{4} / \mathrm{g}$ sorghum straw (dry weight) in a solid:liquid ratio of 1:10. Thereafter, the hydrolysate was filtered and concentrated under vacuum at $70 \pm 5^{\circ} \mathrm{C}$ to increase xylose concentration threefold. In order to reduce the concentrations of toxic compounds, the hydrolysate was then treated by increasing the initial $\mathrm{pH}$ from 1.27 to 7.0 with $\mathrm{CaO}$ following its reduction to $\mathrm{pH} 2.5$ with $\mathrm{H}_{3} \mathrm{PO}_{4}$ and subsequent treatment with active charcoal adsorption $(1 \% \mathrm{w} / \mathrm{v})$ in Erlenmeyer flasks on a rotary shaker at $200 \mathrm{rpm}, 60^{\circ} \mathrm{C}$, for 30 minutes. The resultant precipitates from all stages of the treatment were removed by vacuum filtration using qualitative filter paper [8].

Fermentation was carried out in triplicate, in $125 \mathrm{~mL}$ Erlermeyer flasks containing $50 \mathrm{~mL}$ of hydrolysate, previously detoxified and autoclaved at $115^{\circ} \mathrm{C}$ for 15 minutes, supplemented with the same nutrients used for inoculum preparation except for xylose, and $\mathrm{pH}$ adjusted by the addition of $\mathrm{NaOH}$ solution to $\mathrm{pH}$ 5.5. The flasks were left under agitation $(200 \mathrm{rpm})$ at $30^{\circ} \mathrm{C}$ for 72 hours.

The concentrations of D-xylose, D-glucose, L-arabinose, xylitol, ethanol and acetic acid were determined by highperformance liquid chromatography (Shimadzu LC-10AD) using a refractive index detector and a Bio-Rad Aminex HPX$87 \mathrm{H}$ column $(300 \times 7.8 \mathrm{~mm})$ at $45{ }^{\circ} \mathrm{C}, 0.01 \mathrm{~N} \mathrm{H}_{2} \mathrm{SO}_{4}$ as an eluent at a $0.6 \mathrm{~mL} / \mathrm{min}$-flow rate and an injection volume of 20 $\mu \mathrm{L}$ [15]. Furfural and 5-hydroxymethylfurfural were determined with a UV detector (SPD-10A UV-VIS) and a Hewllet-Packard RP18 column at $25^{\circ} \mathrm{C}$, acetonitrile/ $\mathrm{H}_{2} \mathrm{O}(1: 8)$ plus $1 \%$ acetic acid as eluent, injection volume of $20 \mu \mathrm{L}$ [15]. Phenolic compounds were estimated by UV-VIS spectrometry by the Folin-Ciocalteau method [21]. Cell concentrations were monitored by following absorbance readings $(600 \mathrm{~nm})$ of $3 \mathrm{~mL}$ samples which were correlated with dry cell mass $(\mathrm{g} / \mathrm{L})$ using a standard curve.

The partial characterization of sorghum straw hemicellulosic hydrolysate, obtained after diluted acid hydrolysis with $\mathrm{H}_{2} \mathrm{SO}_{4}$, showed a high xylose content (17.69 $\mathrm{g} / \mathrm{L}$ ) regarding other sugars (glucose $2.1 \mathrm{~g} / \mathrm{L}$ and arabinose 1.81 $\mathrm{g} / \mathrm{L})$, and a low glucose:xylose ratio (1:8). Although repression of xylose utilization by glucose is well known in yeasts, similar glucose:xylose ratios improved xylitol production in C. guilliermondii [20].

Concerning the presence of toxic compounds released during the acid hydrolysis of sorghum straw, it can be observed that acetic acid $(1.87 \mathrm{~g} / \mathrm{L})$ and phenols $(2.12 \mathrm{~g} / \mathrm{L})$ are the main inhibitors, but their content as well as furfural $(0.04 \mathrm{~g} / \mathrm{L}), 5$ HMF (1.56 g/L) and metal concentrations (Ni $0.009 \mathrm{~g} / \mathrm{L}, \mathrm{Cr}$ $0.017 \mathrm{~g} / \mathrm{L}, \mathrm{Zn} 0.007 \mathrm{~g} / \mathrm{L}, \mathrm{Fe} 0.022 \mathrm{~g} / \mathrm{L}$ and $\mathrm{Ca} 0.2 \mathrm{~g} / \mathrm{L})$ do not exceed the range found in other hemicellulosic hydrolysates [2, $8,11,25]$ as well as in sorghum straw hydrolysates [6, 19, 23] obtained under different conditions.

Detoxified threefold concentrated hydrolysate presented the following composition $(\mathrm{g} / \mathrm{L})$ : glucose $4.30 \mathrm{~g} / \mathrm{L}$; xylose $43.78 \mathrm{~g} / \mathrm{L}$; arabinose $4.32 \mathrm{~g} / \mathrm{L}$; acetic acid $3.13 \mathrm{~g} / \mathrm{L}$; furfural 
$0.05 \mathrm{~g} / \mathrm{L} ; 5-\mathrm{HMF} 1.52 \mathrm{~g} / \mathrm{L}$ and total phenols $1.36 \mathrm{~g} / \mathrm{L}$. When compared to the untreated hydrolysate (data not shown), moderate removals of phenolic compounds $(67 \%)$ and acetic acid $(31 \%)$ were obtained with the detoxification process employed, i.e., overliming combined with activated charcoal. Previous reports have shown that overliming and activated charcoal treatment did not largely affect acetic acid concentration [12,25], whereas activated charcoal was efficient for the reduction of furan derivatives in different types of hemicellulosic hydrolysates [8,25]. However, the results of several researches have shown that treatment with active charcoal was dependent on variables as temperature, contact time, hydrolysate:charcoal ratio and $\mathrm{pH}$ with a significant effect on detoxification of sugarcane bagasse hydrolysate [8], rice straw hydrolysate [10] and in sorghum straw hydrolysate [19]. Phenolic compounds are shown to be the major inhibitors in lignocellulosic hydrolysates [12] and can be more easily removed with anion-exchange resin treatments [2,25], although these are onerous processes. Overliming and activated charcoal adsorption are the most economical treatments for hydrolysates. Moreover, the precipitates containing calcium ions formed during overliming may be used to correct soil acidity without environmental damage.

The experimental results of batch fermentation of sorghum straw hemicellulosic hydrolystate by C. guilliermondii are shown in Figures 1A and B. According to Figure 1A, glucose was not detected in the medium after 6 hours. Repression of xylose utilization by glucose was not observed and probably occurred before this period. Xylose was consumed at a rate of $19-26 \%$ up to 48 hours (calculated as instantaneous, i.e., in 12-hour intervals), which increased to 36$37 \%$ afterwards. The biomass concentration profile shows a faster growth up to 6 hours, which coincided with glucose depletion. After this period, specific growth rate $\left(\mu_{\mathrm{X}}\right)$ decreased from $0.119 \mathrm{~h}^{-1}$ to $0.013 \mathrm{~h}^{-1}$. Although xylose consumption was observed after 6 hours, xylitol formation initialized only after 24 hours, which indicates that xylose utilization during the first
24 hours was directed to growth. These results are in agreement with previous studies which support that xylitol production is not-growth-related, but a consequence of redox inbalance [5].

Ethanol formation was faster in the first 24 hours of fermentation (Figure 1B), probably due to the presence of glucose and the poor contribution of xylose and arabinose to its formation. After 24 hours, ethanol production was negligible and reached a maximum of $2.8 \mathrm{~g} / \mathrm{L}$. Ethanol, a byproduct of xylose-xylitol conversion, was also found during the growth of C. guilliermondii in semidefined medium [5] and sugarcane hemicellulosic hydrolysate [16] and its formation was dependent on the medium $\mathrm{pH}$ [14].

Figure 1B shows the acetic acid concentration throughout the fermentation. This acid was slowly and concurrently assimilated with xylose, resulting in a slight increase in $\mathrm{pH}$ values. Almost $28 \%$ of acetic acid was assimilated within up to 72 hours. Despite toxicity of acetic acid to yeast metabolism, its consumption was previously observed in experiments with C. guilliermondii and the toxicity degree was related to several environmental factors, mainly its concentration in the culture medium. When present in low concentration $(1 \mathrm{~g} / \mathrm{L})$ in the medium, acetic acid can increase xylitol production by $C$. guilliermondii [4] and the higher the degree of cell adaptation, the higher the capacity of $C$. guilliermondii cells to metabolize acetic acid [18], resulting in significant increases in fermentative parameters.

Table 1 summarizes fermentative parameters of $C$. guilliermondii grown in sorghum straw hydrolysate. The highest xylitol yield $(0.44 \mathrm{~g} / \mathrm{g})$, corresponding to $48 \%$ of the theoretical based on xylose, and the highest productivity $(0.19$ $\mathrm{g} / \mathrm{Lh}$ ) were obtained after 72 hours of fermentation, although yields up to $75-97 \%$ have often been reported with this yeast in other hemicellulosic hydrolysates $[10,16,18,25]$. In the present assay, $6.9 \mathrm{~g} / \mathrm{L}$ of xylose still remained in the medium. If the cultivation time was prolonged, the final amount of xylitol estimated would be $16.6 \mathrm{~g} / \mathrm{L}$, considering the same 
xylitol yield verified at 72 hours and still adequate nutritional conditions.

The possibility of using detoxified sorghum straw hydrolysates for xylitol production was confirmed in fermentation with $C$. parapsilosis, in which a maximal xylitol concentration of $17 \mathrm{~g} / \mathrm{L}$, a product yield of $0.27 \mathrm{~g} / \mathrm{g}$ and a productivity of $0.12 \mathrm{~g} / \mathrm{Lh}$ were obtained. These values were higher than those obtained with that yeast in synthetic media [19]. In the present study, C. guilliermondii did not show appreciable fermentative performance when compared to previous results with such yeast in synthetic media and in other hemicellulosic hydrolysates. This is probably due to interactive effects of inhibitory compounds. It is worth noting that little is currently known regarding the effect of metals ions in the culture medium, the maximum allowed concentration for each one as well as the simultaneous presence of several other inhibitors on xylose metabolism. Further studies are necessary to establish an adequate acid hydrolysis and an adequate process of detoxification of sorghum straw hemicellulosic hydrolysate aiming at achieving an efficient conversion of xylose to xylitol with $C$. guilliermondii. Additionally, considering that hemicellulosic fraction is easily extracted from biomass and that pentoses can be co-fermented to ethanol by genetically engineered yeasts, the efforts of recovering xylose from sorghum straw as well as an economical hydrolysis of cellulose can offer a potential approach to ethanol production.

A

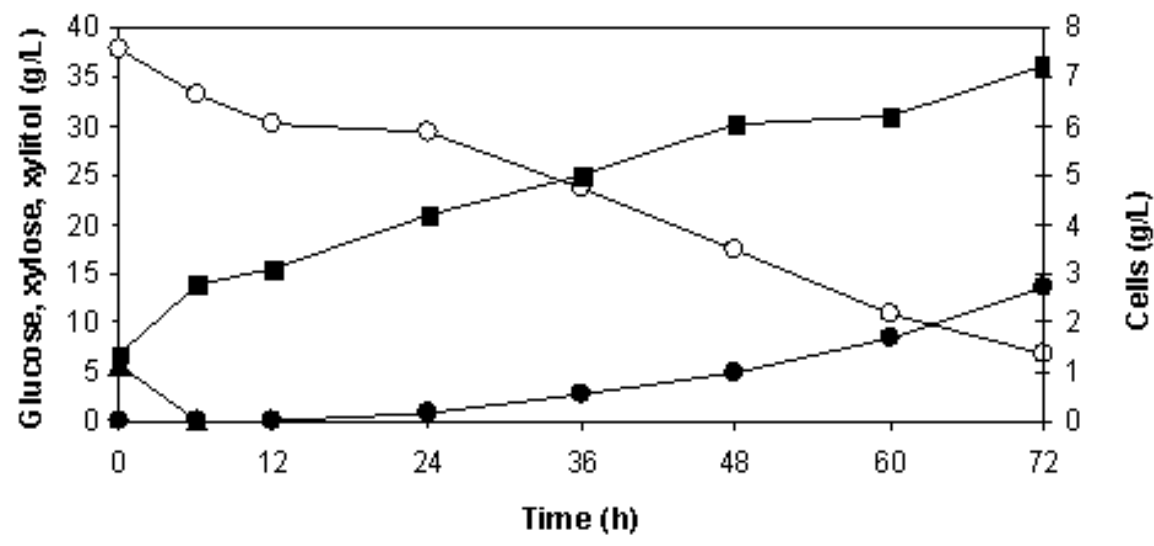

B

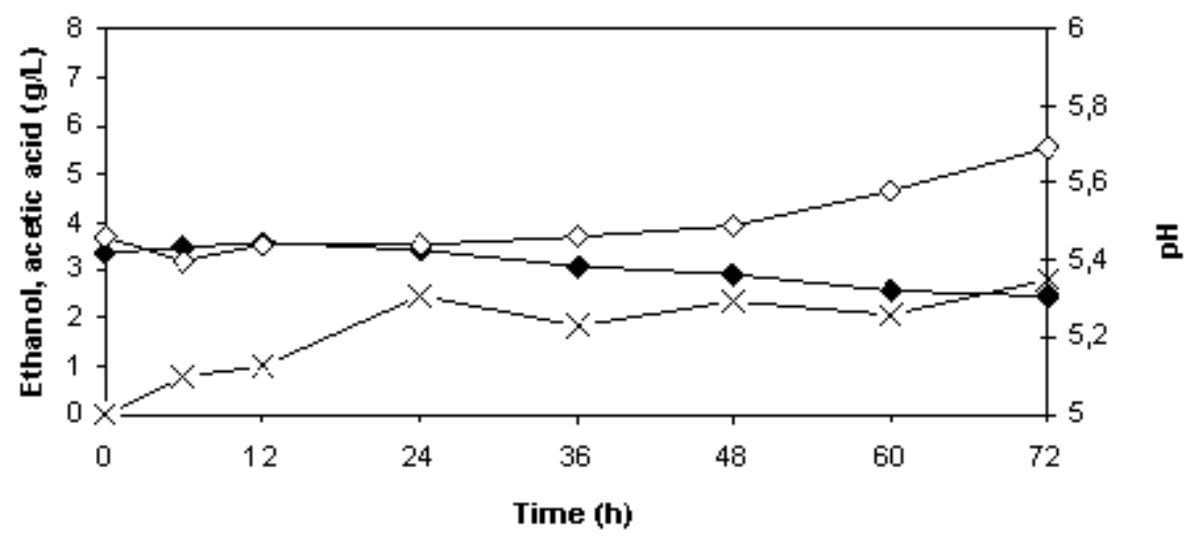

Figure 1. Variation of $\mathrm{A}-$ concentration $(\mathrm{g} / \mathrm{L})$ of glucose $(\boldsymbol{\Delta})$, xylose $(\mathrm{O})$, xylitol $(\bullet)$ and cells $(\boldsymbol{\bullet})$, B - concentration $(\mathrm{g} / \mathrm{L})$ of ethanol $(\mathrm{x})$ and acetic acid $(\diamond)$ and $\mathrm{pH}(\diamond)$ during the 72-hour fermentation of in sorghum straw hemicellulosic hydrolysate by $C$. guilliermondii. 
Table 1. Experimental parameters attained during the 72-hour fermentation of sorghum straw hemicellulosic hydrolysate by $C$. guilliermondii.

\begin{tabular}{ccccccc}
\hline $\begin{array}{c}\text { Time } \\
(\mathbf{h})\end{array}$ & $\begin{array}{c}Q_{S} \\
(\mathbf{g} / \mathbf{L h})\end{array}$ & $\begin{array}{c}\boldsymbol{Y}_{X / S} \\
(\mathbf{g} / \mathbf{g})\end{array}$ & $\begin{array}{c}Q_{X} \\
(\mathbf{g} / \mathbf{L h})\end{array}$ & $\begin{array}{c}\boldsymbol{Y}_{\boldsymbol{P} / S} \\
(\mathbf{g} / \mathbf{g})\end{array}$ & $\begin{array}{c}Q_{P} \\
(\mathbf{g} / \mathbf{L h})\end{array}$ & $\begin{array}{c}\eta \\
(\%)\end{array}$ \\
\hline 24 & 0.35 & 0.5 & 0.18 & 0.11 & 0.04 & 12 \\
48 & 0.43 & 0.3 & 0.13 & 0.24 & 0.1 & 26 \\
72 & 0.43 & 0.24 & 0.1 & 0.44 & 0.19 & 48 \\
\hline
\end{tabular}

$Q_{s}$ Volumetric xylose uptake rate (g/Lh)

$Q_{x}$ Volumetric cell production rate $(\mathrm{g} / \mathrm{Lh})$

$Q_{p}$ Volumetric xylitol production rate $(\mathrm{g} / \mathrm{Lh})$

$Y_{x / s}$ Cell yield coefficient, $\mathrm{g}$ dry cell mass per $\mathrm{g}$ xylose consumed $(\mathrm{g} / \mathrm{g})$

$Y_{p / s}$ Xylitol yield coefficient, g xylitol per g xylose consumed $(\mathrm{g} / \mathrm{g})$

$\eta_{\text {xylitol }}$ percentage of xylitol yield from the theoretical value (\%)

\section{REFERENCES}

1. Ballesteros, M; Oliva, J.M.; Negro, M.J.; Manzanares, P.; Ballesteros, I. (2004). Ethanol from lignocellulosic materials by a simultaneous saccharification and fermentation process (SFS) with Kluyveromyces marxianus CECT 10875. Process Biochem. 39 (12), 1843-1848.

2. Carvalheiro, F.; Duarte, L.C.; Lopes, S.; Parajó, J.C.; Pereira, H.; Gírio, F.M. (2005). Evaluation of the detoxification of brewery's spent grain hydrolysate for xylitol production by Debaryomyces hansenii CCMI 941. Process Biochem. 40 (3), 1215-1223.

3. Felipe, M.G.A. (2004). Biotechnological production of xylitol from lignocellulosic materials. In: Saha, B.C.; Hayashi, K. (eds). Lignocellulose biodegradation, vol. 889. American Chemical Society, Washington, D.C., USA, p.300-315.

4. Felipe, M.G.A.; Vieira, D.C.; Vitolo, M.; Silva, S.S.; Roberto, I.C.; Mancilha, I.M. (1995). Effect of acetic acid on xylose fermentation to xylitol by Candida guilliermondii. J. Basic Microbiol. 35 (3), 171-177.

5. Granström, T.; Ojamo, H., Leisola, M. (2001) Chemostat study of xylitol production by Candida guilliermondii. Appl. Microbiol. Biotechnol. 55 (1), 36-42

6. Herrera, A.; Téllez-Luis, S.J.; González-Cabriales, J.J.; Ramírez, J.A.; Vázquez, M. (2004). Effect of the hydrochloric acid concentration on the hydrolysis of sorghum straw at atmospheric pressure. J. Food Eng. 63 (1), 103-109

7. Manz, U.; Vanninen, E.; Voirol, F. (1973). Xylitol - its properties and use as a sugar substitute in foods. Food R. A. Symp. Sugar and Sugar Replacements, London, UK

8. Marton, J.M.; Felipe, M.G.A.; Silva, J.B.A.; Pessoa Junior, A. (2006). Evaluation of the activated charcoals and adsorption conditions used in the treatment of sugarcane bagasse hydrolysate for xylitol production. Braz. J. Chem. Eng. 23 (1), 9-21.
9. Melaja, J.; Hämälainen, L. February 1977. Process for making xylitol. US. Pat. 4,008,285

10. Mussatto, S.I.; Roberto, I.C. (2001). Hydrolysate detoxification with activated charcoal for xylitol production by Candida guilliermondii. Biotechnol. Lett. 23 (20), 1681-1684.

11. Mussato, S.I.; Roberto, I.C. (2004). Optimal experimental conditions for hemicellulosic hydrolyzate treatment with activated charcoal for xylitol production. Biotechnol. Progress 20 (1), 134-139.

12. Palmqvist, E.; Hahn-Hägerdal, B. (2000). Fermentation of lignocellulosic hydrolysates. I: inhibition and detoxification. Biores. Technol. 74 (1), 1724.

13. Rani, K.S.; Swamy, M.V.; Seenayya, G. (1998). Production of ethanol from various pure and natural cellulosic biomass by Clostridium thermocellum strains SS21 and SS22. Process. Biochem. 33 (4), 435-440.

14. Roberto, I.C.; Silva, S.S.; Felipe, M.G.A.; Mancilha, I.M.; Sato, S. (1996). Bioconversion of rice straw hemicellulose hydrolysate for the production of xylitol: effect of $\mathrm{pH}$ and nitrogen source. Appl. Biochem. Biotechnol. 57-58 (1), 339-347 .

15. Rodrigues, R.C.L.B.; Felipe, M.G.A.; Silva, J.B.A.; Vitolo, M.; Gómez, P.V. (2001). The influence of $\mathrm{pH}$, temperature and hydrolysate concentration on the removal of volatile and non-volatile compounds from sugarcane bagasse hydrolysate treated with activated charcoal before or after vacuum evaporation. Braz. J. Chem. Eng. 18 (3), 299-311.

16. Rodrigues, R.C.L.B.; Sene, L.; Gilvane, S.M.; Roberto, I.C.; Pessoa Jr., A.; Felipe, M.G.A. (2006). Enhanced xylitol production by precultivation of Candida guilliermondii cells in sugarcane bagasse hemicellulosic hydrolysate. Curr. Microbiol. 53 (1), 53-59.

17. Sanches, B.; Bautista, J. (1998). Effects of furfural and 5hydroxymethylfurfural on the fermentation of Saccharomyces cerevisiae and biomass production from Candida guilliermondii. Enzyme Microb. Technol. 10 (5), 315-318. 
18. Sene, L.; Felipe, M.G.A.; Vitolo, M.; Silva, S.S.; Mancilha, I.M. (1998) Adaptation and reutilization of Candida guilliermondii cells for xylitol production in bagasse hydrolysate. J. Basic Microbiol. 38 (1), 61-69 .

19. Sepúlveda-Huerta, E.; Tellez-Luis, S.J.; Bocanegra-García, V.; Ramírez, J.A.; Vázquez, M. (2006). Production of detoxified sorghum straw hydrolysates for fermentative purposes. J. Sci. Food. Agric. 86 (15), 2579-2586.

20. Silva, D.D.V.; Felipe, M.G.A. (2006). Effect of glucose:xylose ratio on xylose reductase and xylitol dehydrogenase activities from Candida guilliermondii in sugarcane bagasse hydrolysate. J. Chem. Technol. Biotechnol. 81 (7), 1294-1300.

21. Singleton, V.L.; Orthofer, R.; Lamuela-Raventós, R.M. (1999). Analysis of total phenols and other oxidation substrates and antioxidants by means of Folin-Ciocalteau reagent. In: Packer, L. (ed.) Methods in Enzymology, vol. 299: Academic Press, New York, USA, p.152-178.

22. Sonia, K.G.; Chadha, B.S.; Saini, H.S. (2005). Sorghum straw for xylanase hyper-production by Thermomyces lanuginosus $\left(\mathrm{D}_{2} \mathrm{~W}_{3}\right)$ under solid-state fermentation. Biores. Technol. 96 (14), 1561-1569.

23. Téllez-Luis, S.J.; Ramírez, J.A.; Vázquez, M. (2002). Mathematical modelling of hemicellulosic sugar production from sorghum straw. $J$. Food Eng. 52 (3), 285-291.

24. Vázquez, M.; Oliva, M.; Téllez-Luis, S.J.; Ramírez, J.A. (2007). Hydrolysis of sorghum straw using phosphoric acid: Evaluation of furfural production. Biores. Technol. 98 (16), 3053-3060.

25. Villarreal, M.L.M.; Prata, A.M.R.; Felipe, M.G.A.; Almeida e Silva, J.B. (2006). Detoxification procedures of Eucalyptus hemicellulose hydrolysate for xylitol production by Candida guilliermondii. Enzyme Microb. Technol. 40 (1), 17-24. 